\title{
A Crossroads of Seven Streets: A Control Mechanism of Trilingual Scientific Texts Translations
}

\author{
Christidou Sofia \\ University of Western Macedonia, Thessaloniki, Greece
}

\begin{abstract}
This paper is part of a published thesis which analyses translators' and special scientists' behaviors towards the Greek language use in the field of linguistics and the differentiations presented in translated versions of terms in Greek academic textbooks. It explores the strategies employed throughout the translation process and seeks to reveal whether innovations in terminology have been accepted by the linguistic-translators' community and to what extent, or if scientists tend to prefer foreign terms or turned-into-Greek versions instead of their purely Greek equivalents. The tools used were the manual processing and contrastive analysis of indexes of terms using Dirk Delabastita's translation strategies out of which we created an elaboration tool consisting of seven variables and the psychometric questionnaires. The results displayed a variation in the attitudes of the academic textbooks translators and the questionnaire research subjects.
\end{abstract}

Keywords: translation strategies, indexes, psychometric tests, technical translation, translators' training

\section{Introduction}

The present paper is part of a thesis that was presented in public in July 2014 (published on the site of the Greek National Documentation Center) which analysed the translators' behaviors and strategies as far as the Greek language use is concerned in the fields of linguistics and telecommunications. It also examined the views of undergraduate, postgraduate students, and graduates of foreign languages departments, departments of primary education and early childhood education with a linguistic background, as well as translators in relation to the differentiations presented in translated versions of linguistic and telecommunication terms in Greek in various academic textbooks. For the needs of this thesis, we examined in detail the indexes of terms of four linguistic (two English and two French) and four telecommunications textbooks (English) - originals and their translations - with the use of the translation strategies developed by the Belgian translatologist Dirk Delabastita through which we created an elaboration tool consisting of seven variables (we added here an extra strategy). Here, due to lack of space, we are going to discuss only a number of the English and French linguistic terms.

In particular, our research aims at exploring the translation strategies employed by the translators throughout the translation process. It seeks to reveal whether various innovations in terminology translation have become widely accepted by the linguistic-translators' community and to what extent, and if the prevailing confusion on

Christidou Sofia, Special Scientific Staff, Ph.D. in Translatology (Translation Criticism), Department of Mechanical Engineering, School of Engineering, University of Western Macedonia. 
the matter, due to the existence of different translations provided by linguists-translators, causes the special scientists to eventually prefer foreign terms or their turned-into-Greek versions instead of a purely Greek equivalent term.

The tools which were used in order to achieve the above aims were the thorough processing and contrastive analysis of indexes of terms and the psychometric questionnaires we created based on linguistic academic textbooks. The data that came to light underwent both a qualitative and a quantitative analysis.

\section{Theoretical Framework}

\section{Translation as an Object of Translatology}

For the needs of this paper translatology is quoted with a broader sense, even though the approach of Jean René Ladmiral (1979) is considered purely translatological. This happens because he follows the via media of the various translation theories. One can understand that by the fact that he chooses to examine philosophical texts. Undeniably, philosophical texts are classified amongst literary and technical-scientific texts. In the framework of medium road, Jean René Ladmiral locates the following aspects of translational phenomenon: translational entropy or addition, translational transparency or darkening, cultural elevation or leveling, terminological consistency or ambiguity, linguistic appropriateness or distortion, interpretation or meta-codification. Actually, these are the translator's everlasting questions. The same theorist considers it impossible to give all-embracing and specific answers and he claims that the unique judgment factor is each text separately and its translation pair. This moderate attitude becomes more obvious when compared to more extreme ones. Antoine Berman (1985, pp. 35-41) on the other hand examines the source language and considers that translators are always in confusion and are followed by the guilt regarding the faithfulness or faithlessness towards the original text or its translation. The moral tendency, though, is that translation should cover the original text but, at the same time, also bring it forward through the abolition of ethnocentrism and the promotion of interlingual and cultural consciousness. Beyond this extremity, though, he accepts the necessity for a translation discipline which will derive not only from linguistics, literature studies, stylistics, or any other discipline but will be in constant interaction with all of them.

On the other edge, the one that focuses on the target language, lies Gideon Toury (1995, pp. 172-175), who calls his views "target-oriented". Important are his remarks on the ambiguity of "literary translation" (in Greek, this has a dual meaning thus the translation of literature texts or the word-for-word translation) and the classification of translation in: linguistically-motivated, textually-dominated, and literary or word-for-word translation. We should mainly, though, highlight his comments on the existence of a cultural distance between source language and target language, reinforcing his view on the respect towards the target language.

Surely not "extremist" but also not a representative of the via media is Peter Newmark. One could claim that his views are the first ones to get closer to technical translation. Newmark, in general, believes that a translation theory can neither be universal nor can it turn a bad translator to a good one. It can definitely, though, reveal bad writing and bad translation and for what reason, and at the same time it can suggest basic principles and guidelines some of which can be rather contradictory. Then he draws a distinction between communicative and semantic translation. The former includes the translation of non literary texts and focuses on the reader and the target language. On the other hand, the latter includes the translation of literary texts and places emphasis on the source language and the source text viewing it from a morphological and a content point of view. Furthermore, 
another innovation of his is the explanation of literary ("faithful" or word-for-word) translation. Not only does he consider it the best method, but also the unique valid one, only when an equivalent result is achieved. And this can happen in "authentic" texts, especially in their standardized part. Hence, the translator's task is to find these "authentic" translations and not to create his own versions. Ultimately, he mentions the "small" - but actually "big"- problems of translation such as the translation of proper names, institutions, cultural meanings, metaphors - according to him the most significant—but also of the terms that until then were ignored by the various theories of translation (Newmark, 1995, pp. 38-56; Newmark, 2005, pp. 46-47).

The distinction of text types introduced by Peter Newmark is intensely extended as an analytical strategy by Katharina Reiss (1983, pp. 18-23) and the typological approach which she represents. According to it, the success of the translation mainly depends on whether the translator is aware of the type of the original text and maintains the special features that condition it. The text types are grouped in three basic types: informative, expressive, and operative texts. Each one's characteristics are clearly depicted by their naming. The first type aims at conveying information, so consequently the translation focuses on the precise communication of the information content. The second type is featured by the existence of an artistic or aesthetic style and as a result the translation has to respect the special characteristics of the original's form. Finally, the third type aims at persuading or dissuading, that is cajoling the reader, and as a consequence the translator's job lies in achieving the same impact on the reader as the original.

At the description of the aforementioned features the concept of Skopos is innate, a concept that becomes the fundamental term of Christiane Nord's (1997, p. 9) translation theory, who continues the thinking of Katharina Reiss. Christiane Nord introduces the functionalist study and translation criticism. After having performed a historical retrospect and reviewed other translation theorists of functionalism like Hans J. Vermeer, she presents the "Theory of Action" and the "Skopostheorie/Theory of Skopos". In the first case, translating is conceived as "Intentional" and "Interpersonal Interaction", as well as "Communicative" and "Intercultural Action", also entering the field of "Text-Processing". In the second case, as one can understand by its naming, the "intention" and the "aim (purpose, skopos)" of the original text are being studied as components of translation, along with the abiding relationship with the "intratextual coherence". Definitely the intratextual coherence is based on the morphosyntactic rules of the target language that guide the text syntax.

Werner Koller (1992, pp. 214-236), who also forms part of the German "school", comments on the multi-used concept of equivalence (Äquivalenz), placing emphasis on denotative equivalence (denotative Äquivalenz), and spots translation strategies (Übersetzungsverfahren) that consist of particular types of correspondence (Entsprechungstypen): one-to-one correspondence (Eins-zu-eins-Entsprechung), one-to-many correspondence or diversification (Eins-zu-viele-Entsprechung/Diversifikation), many-to-one correspondence or neutralization (Viele-zu-eins-Entsprechung/Neutralisation), one-to-zero correspondence or blank (Eins-zu-Null-Entsprechung/Lücke), one-to-part correspondence (Eins-zu-Teil-Entsprechung). There are five suggested ways that the translator can adopt for the one-to-zero or blank correspondence: (1) adoption of the expression in the source language from the target language, either in inverted commas without transliteration or without inverted commas with transliteration according to the phonetic, graphemic, or/and morphologic rules of the target language; (2) loan translation (Lehnübersetzung), where expressions of the source language are translated word-for-word in the target language but the newly created expressions were not existent in the 
language; (3) translation of the expression in the source language from an already existent in the target language with a similar meaning, and primarily, the closest to the meaning of the original expression; (4) the expression of the source language is translated with a word of explanation or annotation in the target language; and (5) adjustment or adaptation, that is substitution of the registered expressions of the source language in specific communicative situations, with a communicative verbal unit of the target language having a function and concept similar to that of the original expression.

Apparently the above views focus on the communicative dimension of the translator. The work of Basil Hatim and Ian Mason (1997, pp. 14-28) is considered to be within this framework, as obviously manifested by its title. Moreover, they stress the communicative aspect of translation, consisting of six parameters which, in their opinion, the translator should take into account and research: (1) cohesion; (2) coherence; (3) intentionality; (4) situationality; (5) intertextuality; and (6) informativity. The first two parameters concern the purely verbal aspect of translation, that is on a morphosyntactic level, the third and fourth the social—in a broader sense — aspect, and the latter two the semantic.

Lots of theorists and researchers followed the functional and communicative study of translation. One of them is Dirk Delabastita (1989), on whose work is based a significant part of the study and search of our translation tool as it is going to be presented below. One can just note that in this case despite the modern theoretical background the suggested typology derives from the ancient rhetorics. However, this is not something striking given the fact that the art of rhetorics has mainly—let not say only—a communicative character, as translation does. Furthermore, this happened with renowned success - naturally on a practical level -in the historical beginnings of translation, as described before.

\section{Translation as an Object of Special Texts Studies}

Special texts study could not possibly be omitted from this paper. By the term "special texts", we generally refer to technical and scientific texts. According to Hann (1992, p. 7) contrary to other areas of translation, which allow certain individuality on the part of the linguist with regard to lexicology and style, technical translation is essentially a decision-making process involving selection of the correct target language rendering from a number of different, context-dependent alternatives. A good literary translator strives to produce a target version which is as elegant and readable as the original, but the technical translator's main priorities are precision and comprehensibility.

The approach of Pierre Lerat stands out when it comes to special text studies (1995, pp. 102-105). In his treatise Les langues spécialisées, he dedicates a chapter to translation mostly insisting on issues related to "terminology of specialized languages (jargon)" ("terminologie des langues spécialisées"). This does not mean that he overlooks the general condition of special texts translation, since he mentions the concept of collocation ("collocation"), which consists of three different perspectives, depending on the way of approach: pragmatic (pragmatique), syntactic (syntaxique), and semantic (sémantique). Thus, Lerat (1995, p. 105) concludes to the distinction amongst "communicative adequacy" (competence) ("adéquation communicative"), syntagmatic combination ("combinaison syntagmatique"), and conceptual connectivity ("connectabilité conceptuelle"). Regarding terminology, his argumentation as a whole aims at the formulation of guidelines for the creation of "more linguistic terminological data bases" ("bases des données terminologiques plus linguistiques"). 
Nevertheless, he openly points out the terminology management problem a translator is faced with, especially when using bilingual or multilingual dictionaries or terminology databases. At this point, two crucial points of his discussion are worth mentioning. Firstly, special-texts-translation increasingly concerns experts in the related to the scientific field text who are largely bilingual. As far as the understanding of the text is concerned, they are the best judges and, what is more, they are capable of knowing how to name in their respective professional or scientific field. Therefore, the advantage of the special texts translator can only be linguistic. His second point lies in a very representative phrase: “...in order to be scientific, special English cannot be anything less but English!” (Lerat, 1995, p. 105). This means that in every case of scientific or special idiolect, one has to use the morphosyntactic rules typical of the language of this idiolect.

The latter view contradicts another important approach to the study of special texts developed in the Anglo-Saxon academic field. The main concept of this approach is "sublanguage", having its own vocabulary as well as its own "specialized grammar", i.e., with its own morphosyntactic rules. This last property is definitely not acceptable. There cannot be another grammar in the same language as if it were a different language! In any case, the development of this theory regarded the automatic text processing and we theorize that the reasons for that were the poor results out of full grammar use.

\section{Linguistics}

Linguistic terminology in the Greek language stems from the traditional terminology of literary and historical studies which, in many cases, is of Greek origin and has been transferred unabridged into other languages especially in English. Apart from that source, modern terminology comes mainly from translation loans from languages other than Greek to which those who are involved in research and teaching in Greece have to resort to (Babiniotis, 1998, pp. 15-18). Let us bear in mind that scientific terminology is a product of scientific activity which, to a great extent, is conducted in and spread through the English language. Terminology translation is quite often inappropriate as it detaches itself from generally accepted terms.

According to Xydopoulos (2002, pp. 495-506), all translated publications of linguistic texts in the Greek language involve a certain amount of difficulty in their translation as well as in the consolidation of terminology, while often they differ significantly from each other. The factors that contribute in this increased difficulty in the translation and consolidation of terminology are the following: (1) existence of multiple terms in the Greek language for the definition of a single foreign scientific term and (2) use of a single term as a translation of various scientific terms which may have a small or even no relevance to each other.

The problem of linguistics terminology has occupied a line of linguists for many decades and has been discussed thoroughly in academic papers in the past, where a handful of useful reflections were presented (for example the need of unification of terminology, issues of translatability or acceptability, etc.). As early as 1984, Petrounias (1984, pp. 30-32) describes factors that are related with questions of comprehension of Greek scientific terminology and in a broader sense of linguistic terms: (1) Scientific terms change content more rapidly than other words because scientific perceptions also change at the same pace; (2) It is quite likely that the term has not been absolutely successful in its first creation; (3) There often exist terms which do not correspond etymologically to their content; (4) When a term does not pass in a new language as a direct loan, but is translated it is quite probable that an error occurs; and (5) In Greek, the possibilities of word formation via loans of Latin 
origin are limited, compared to other European languages, because of the Greek scholar tradition.

It is true that these factors are still in effect today. For this reason we selected to study four of the most important linguistic academic texts of the 20th century. More specifically, the following pairs of books were selected:

(a1) Martinet, André (1980), Éléments de linguistique générale, Paris, Librairie Armand Colin and (a2)

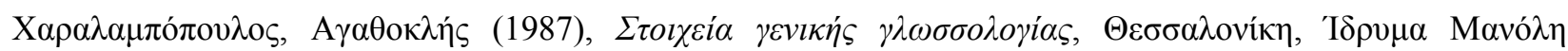

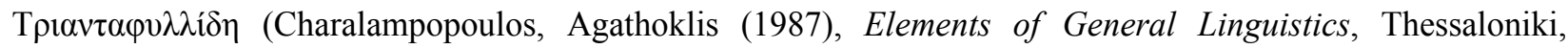
Institution Manolis Triantafyllidis).

(b1) De Saussure, Ferdinand ([1916] 1968 ), Cours de linguistique générale, Paris-Lausanne, Payot and (b2)

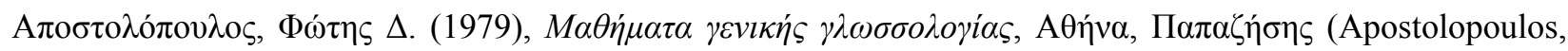
Fotis D. (1979). Courses of General Linguistics, Athens, Papazisis).

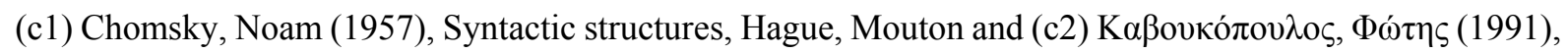

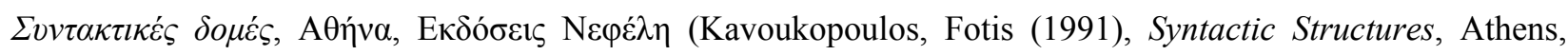
Publications Nefeli.)

(d1) Lyons, John (1981), Language and Linguistics. An Introduction, Cambridge, University of Cambridge

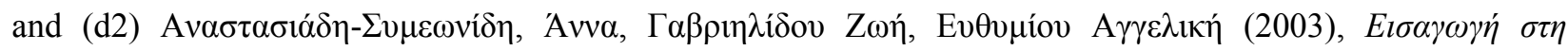

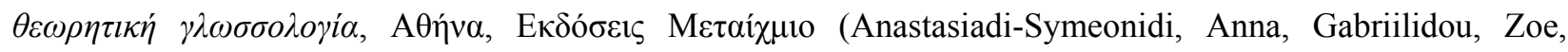
Euthymiou, Angeliki (2003), Introduction to theoretical linguistics, Athens, Metaixmio Publications).

\section{Study of Indexes}

The extensive analysis of indexes presented in this paper was based on the translation strategies developed by the Belgian translatologist Dirk Delabastita (1989, pp. 193-218). Delabastita based the development of his strategies on the techniques used by the ancient Latin rhetoricians, as they were explained by Heinrich Lausberg $(1973,1998)$ in his extensive presentation of the figures of speech used by ancient Greek rhetoricians. These figures of speech were copied by the Latin rhetoricians, starting by Cicero. This typology includes the following translation strategies:

(1) Repetitio: The sign is formally reproduced in an identical manner;

(2) Adiectio: The sign is reproduced with a certain addition;

(3) Detractio: The reproduction is incomplete, it implies a reduction;

(4) Transmutatio: The components of the signs are repeated in a somewhat different internal order, there being an alteration of the sign's textual relations;

(5) Substitutio: The sign is replaced with an altogether different sign.

All the above refer to the lexical, semantic and morphosyntactic level. Hence there is a variant of detractio, where all the elements of the translation unit are erased. This case is considered a different strategy and is called (6) deletio (deletion).

Finally, we added the term (7) non-translation ${ }^{1}$ for the following cases: (a) where the term is not translated,

\footnotetext{
${ }^{1}$ As regards the term non-translation, it may be a term used in the translation theory to distinguish what is and what is not translation. However, there is controversy between the academics as to the circumstances where this term is used. Based on the definition given by the European Society for Translation Studies (EST), the term can refer to fragments of source text preserved in the original language in the target text. Furthermore one of the subcategories classified as non translation is covered by the definition given in the dictionary Translation Terminology (Publications Mesogios, Athens, 2008) for the term "direct transfer".
} 
not even transliterated but appears as it is in the source language; (b) where only part of the term is translated (e.g., a compound term which consists of two terms and has its first part kept in the source language without transliteration while its second one is translated in the target language with the employment of one of the aforementioned strategies); (c) where a term from the original index is omitted from the Greek index; (d) where acronyms and proper names remain in the source language without transliteration; and (e) where the wrong employment of one of the aforementioned strategies leads to a mistake in the translation of a term (Christidou, 2007, p. 36).

The aforementioned typology served as the basis for the study of the terms which were first studied as they appear in the indexes and then processed as they appear in context within the texts. The recording of the terms was done in the alphabetical order of the index in the source language. Term variations, when they appeared, were mentioned under the same entry, even if they had been recorded originally in the book as different entries of the same index. This was done to present the terms in their entirety and, consequently, analyze them in every respect. If the Greek index contained extra terms that did not appear in the original index, those were recorded separately. Then follows the explanation of the translation strategy employed, including comments on the translation process. Moreover, a lexicographic and bibliographic research was performed, and, where necessary, suggestions of more accurate translations were made. Finally a statistical recording of the frequency of appearance of the translation strategies is presented which helps us come to conclusions regarding the decision-making processes.

\section{Index Processing}

\section{Examples of Index Processing}

Table 1

Introduction to Theoretical Linguistics (John Lyons, 1995)

\begin{tabular}{|c|c|c|}
\hline English term & Greek term & Translation strategy \\
\hline $\begin{array}{l}\text { (1) sentence-type (index, p. } 145 \text {, p. } 178 \text { f., p. } 218 \text {, } \\
\text { p. } 441 \text { f.) } \\
\text { (2) } 4.2 .8 \text {, p. } 145,1.32 \\
\text { (3) } 5.2 .6 \text {, p. } 178 \rightarrow \text { types of sentences, } 1.16 \\
\text { (4) } 6.2 .4 \text {, p. } 218 \rightarrow \text { of the sentence-type, } 1.33\end{array}$ & 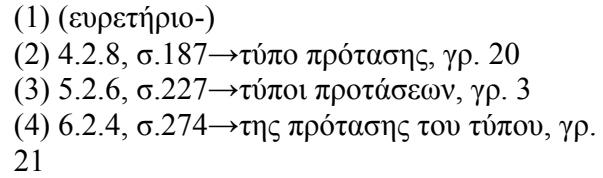 & $\begin{array}{l}\text { (1) non translation } \\
\text { (2) transmutatio } \\
\text { (3) repetitio } \\
\text { (4) repetitio }\end{array}$ \\
\hline
\end{tabular}

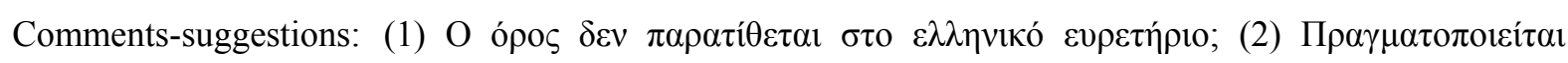

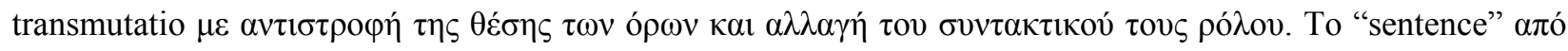

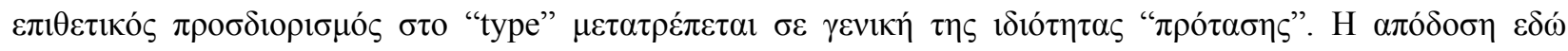

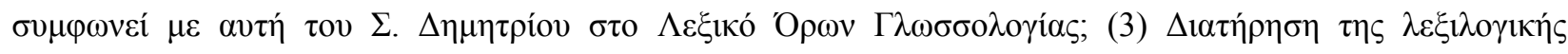

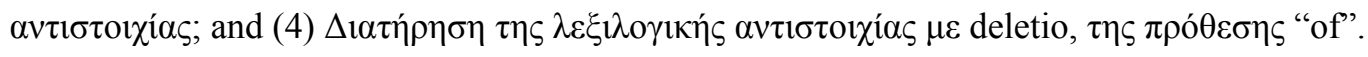

Table 2

Éléments de linguistique générale (André Martinet, 1970)

\begin{tabular}{|c|c|c|}
\hline French $t$ & Greek term & \\
\hline $\begin{array}{l}\text { (1) Abrègement, index, } 6-6 \rightarrow p \\
30,6-14 \rightarrow \text { p. } 1871.18 \text {. } \\
\text { (2) Abrégée } 6-6 \rightarrow \text { p. } 1781.30\end{array}$ & 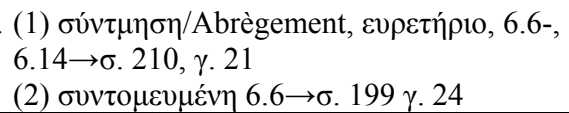 & 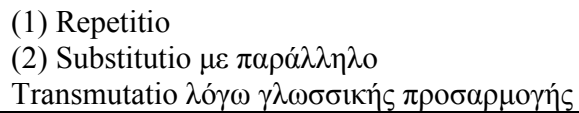 \\
\hline
\end{tabular}




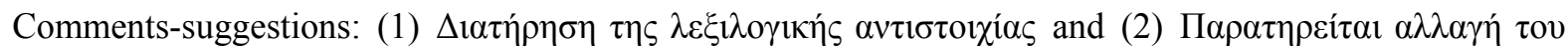

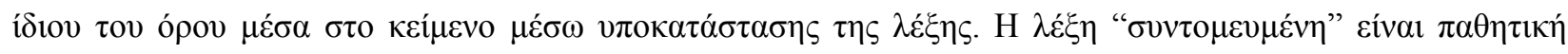

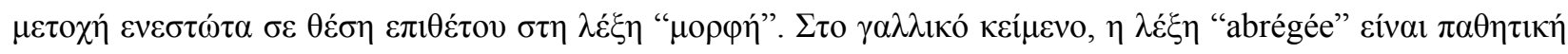

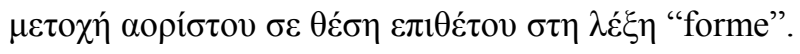

\section{Frequency of Appearance Statistics of Translation Strategies}

Table 3

Frequency of Appearance Statistics of Translation Strategies

\begin{tabular}{lllllll}
\hline & $\begin{array}{l}\text { Introduction to } \\
\text { theoretical linguistics }\end{array}$ & $\begin{array}{l}\text { Syntactic } \\
\text { structures }\end{array}$ & $\begin{array}{l}\text { Éléments de } \\
\text { linguistique générale }\end{array}$ & $\begin{array}{l}\text { Cours de linguistique } \\
\text { générale }\end{array}$ & Total \\
\hline Repetitio & 2042 & 565 & 263 & 314 & 3184 & $78 \%$ \\
Transmutatio & 168 & 85 & 37 & 90 & 380 & $9 \%$ \\
Non-translation & 10 & 0 & 31 & 49 & 90 & $2 \%$ \\
Adiectio & 66 & 15 & 4 & 2 & 87 & $2 \%$ \\
Detractio & 21 & 19 & 0 & 0 & 40 & $1 \%$ \\
Deletio & 11 & 0 & 0 & 1 & 12 & $0 \%$ \\
Substitutio & 256 & 3 & 26 & 6 & 291 & $7 \%$ \\
& 2574 & 687 & 361 & 462 & 4084 & $100 \%$ \\
\hline
\end{tabular}

In conclusion, we can say that when it comes to the linguistic texts repetitio is the translation strategy which prevails and this happens probably because (1) The translations of the original texts took place chronologically far later than their writing so the translations of various terms in Greek were processed and solidified in the Greek language through time and (2) the terms consist mainly of one word hence their translation is less problematic. The second strategy in order of frequency of appearance was that of transmutatio. We might assume that this was due to the different grammatical and syntactical structure of the languages involved which made shifts in grammatical-mostly - categories obligatory. Greek language is a highly inflected language, French is a moderately inflected one, and English is a weakly inflected one.

\section{Questionnaire Research}

As regards linguistic texts, we made a choice of terms which appeared in the translated texts and constituted the basis for the creation of the questionnaires. These choices are called "Texts of reference" or "Terms" and are placed in the first column of the table of the questionnaire. In the second column one can find the "Translated texts", the "Translations", the "Terms", or the "Definitions". The third column contains the answers which have the form of multiple choices A, B, or C. There are 12 questions in total (six for the English linguistic texts and six for the French ones).

The questions are divided in two categories, the ones where the subjects are given three answers for a question out of which one is correct while the other two are misleading (Tsopanoglou, 2000, p. 91) and those where the subjects are given terms in their context with their corresponding translations and are asked to select which one they consider correct. In the second category, which involves the recognition and use of a term within its context, there are not any absolutely correct or wrong answers according to the Greek bibliography since we are dealing here with terms for which in the past there has been intense dispute among linguists. In the present 
paper, due to lack of space, we will selectively present three questions from the English language questionnaire (1a-1b, 3 and 6) and three questions from the French one (1, 2, and 4) (More analytically cf. Christidou, 2014).

As far as the type of the questionnaire is concerned, it is a test of special abilities that aims to measure specific knowledge in linguistic mainly level with scientific parameters. Its content is common for all research subjects and its results are comparable. Moreover, in order to answer the questionnaire, the research subjects have to match elements of the first column with the elements of the second one, fact which reduces, in a satisfactory degree, the probability of answering randomly, ensuring in this way the reliability of the questionnaire. Its validity is ensured by the fact that it has a time limit of 15 minutes. The homogeneity of subjects, who all share knowledge of Linguistics, allows the generalization of conclusions, ensuring thus exterior validity to the questionnaire. When all the answers-results are gathered, they are processed statistically leading consequently to conclusions on the attitudes of the research subjects towards the use of the Greek language in Linguistics.

\section{Distribution of Questionnaires and Demographics}

The questionnaires, for the most part, were distributed in academic halls during lectures in the Aristotle University of Thessaloniki, in the University of Western Macedonia in Florina. Some others were distributed to teachers of English and French and translators, while a small part of the English and French questionnaires were sent via email in various cities in Greece.

For the needs of this research, 102 questionnaires were distributed (51 for the English language and 51 for the French language). The English questionnaires were answered by 23 subjects who were $20-25$ years old, 11 who were 25-35 years old, and 17 who were 35 years old or older, 11 of whom were men and 40 were women. All held a university degree while 11 of them also held a second degree. 14 of them have done postgraduate studies in disciplines not relevant to linguistics, translation, or didactics while 18 of them have done postgraduate studies relevant to linguistics, translation, or didactics. 19 have had professional experience in translation, 4 of them have worked in a translation agency, while 17 have worked as free lance translators. Apart from the knowledge of the English language, which was common for all 51 subjects, 19 had knowledge of French, while 35 of them knew also another foreign language.

On the other hand, the French questionnaires were answered by 26 subjects aged 20-25 years old, 10 who were aged 25-35 years old, and 15 who were 35 years old or over. 4 of them were men while 47 were women. All held a university degree while 7 of them also held a second degree. 7 of them have done postgraduate studies in disciplines not relevant to linguistics, translation, or didactics while 12 of them have done postgraduate studies relevant to linguistics, translation, or didactics. All 51 participants were Greek native speakers and 2 of them were bilingual. 8 have had professional experience in translation, 2 of them have worked in a translation agency, while 8 have worked as free lance translators. Apart from the knowledge of the French language, which was common for all 51 subjects, 42 had knowledge of English, while 21 of them knew also another foreign language. 


\section{English Questionnaires With Suggested Right Answers}

Table 4

$1^{\text {st }}$ Question $a \& b$ - English

Text of reference
According to the excerpts below which do you think is $\mathrm{O}$ Translations
195, 198)

\section{$1^{\text {st }}$ question a - English}

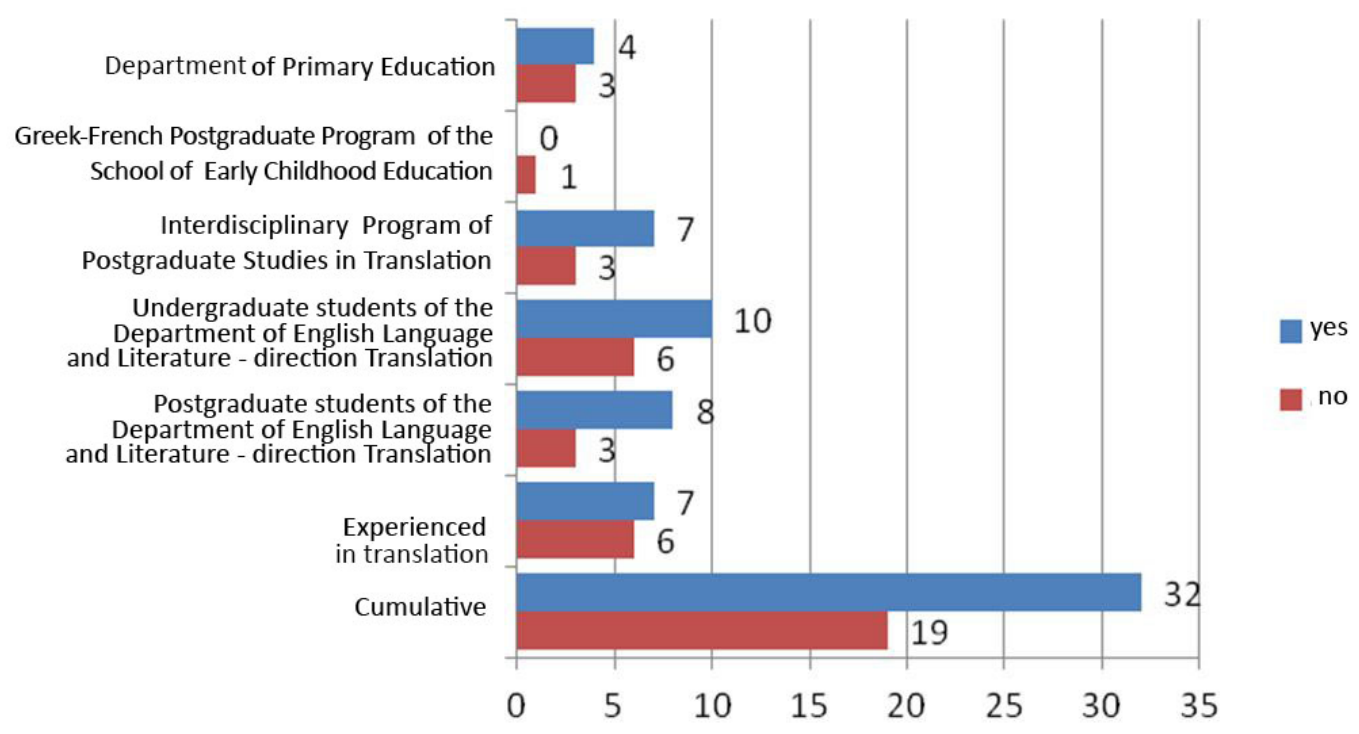

Figure 1. Statistics of question 1a. 


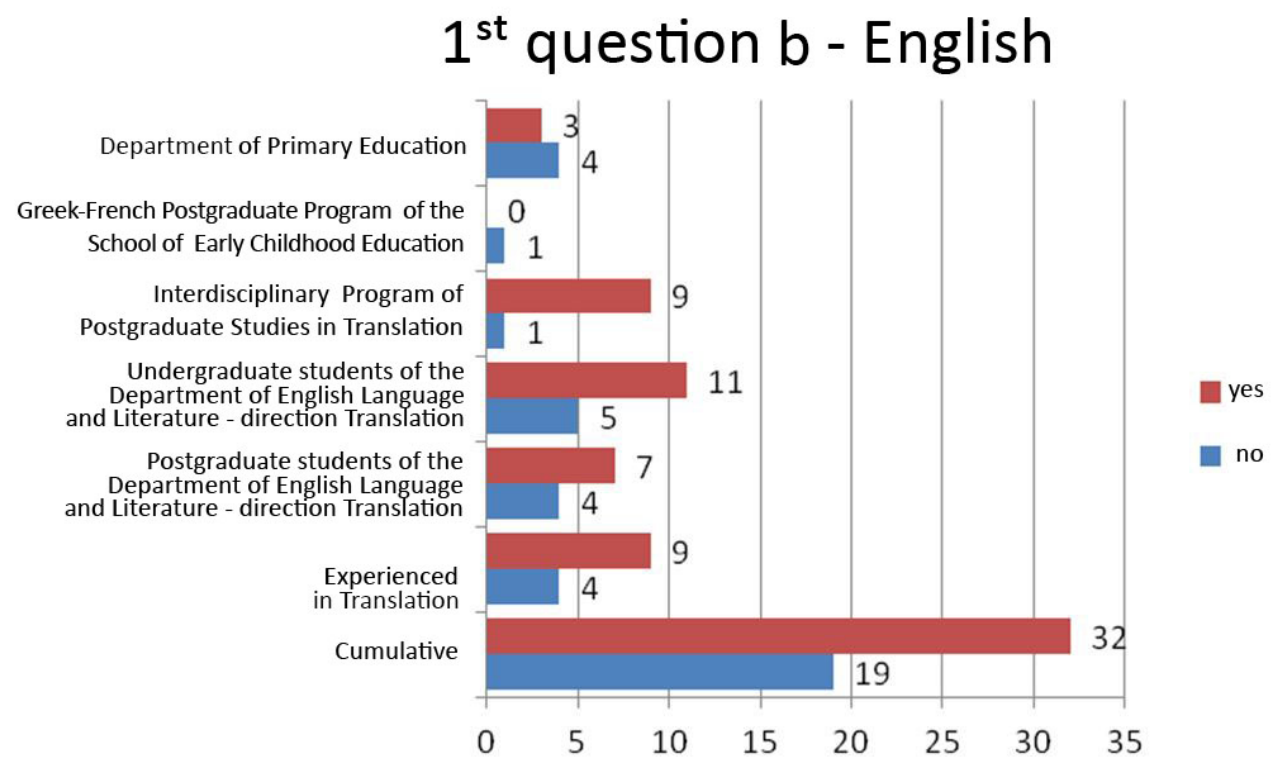

Figure 2. Statistics of question $1 \mathrm{~b}$.

Table 5

$3^{\text {rd }}$ Question - English

\begin{tabular}{|c|c|}
\hline Translations & Answer \\
\hline 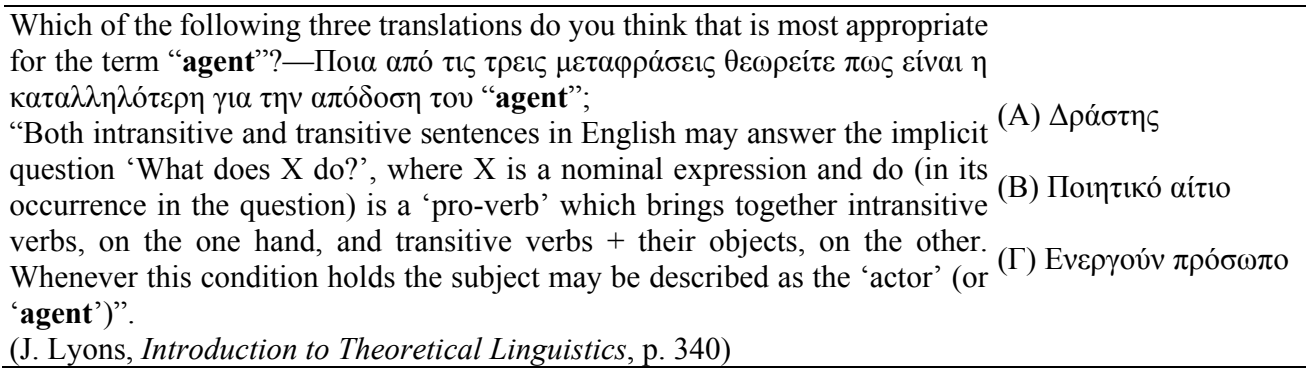 & B \\
\hline
\end{tabular}

\section{$3^{\text {rd }}$ question - English}

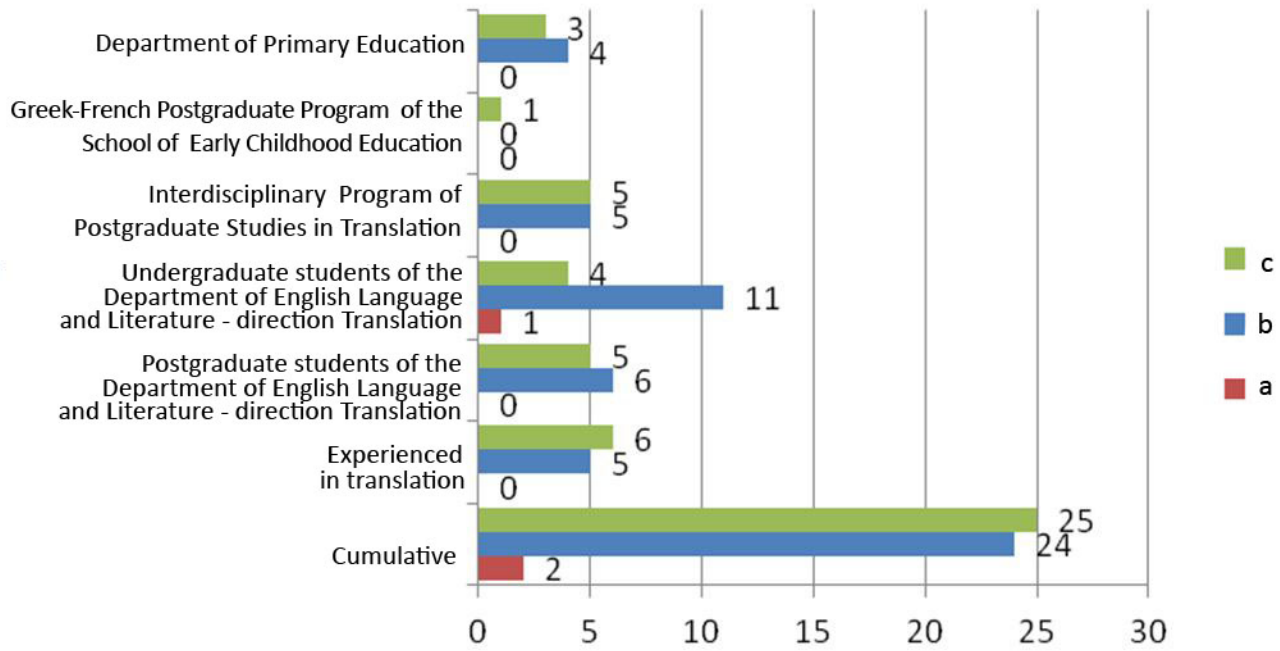

Figure 3. Statistics of question 3. 
Table 6

$6^{\text {th }}$ Question - English

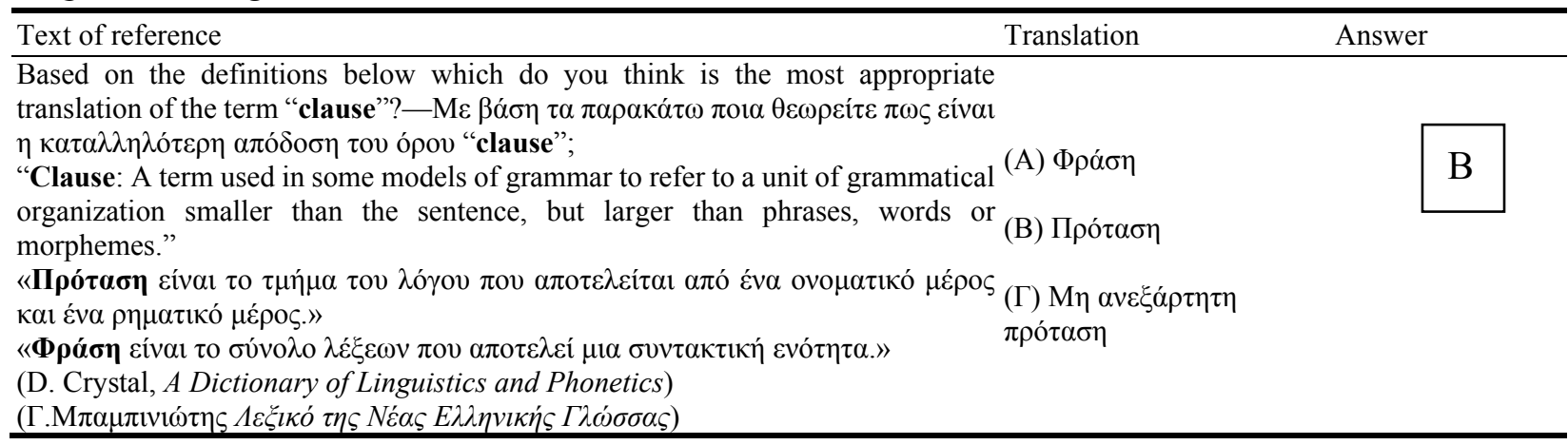

\section{$6^{\text {th }}$ question - English}

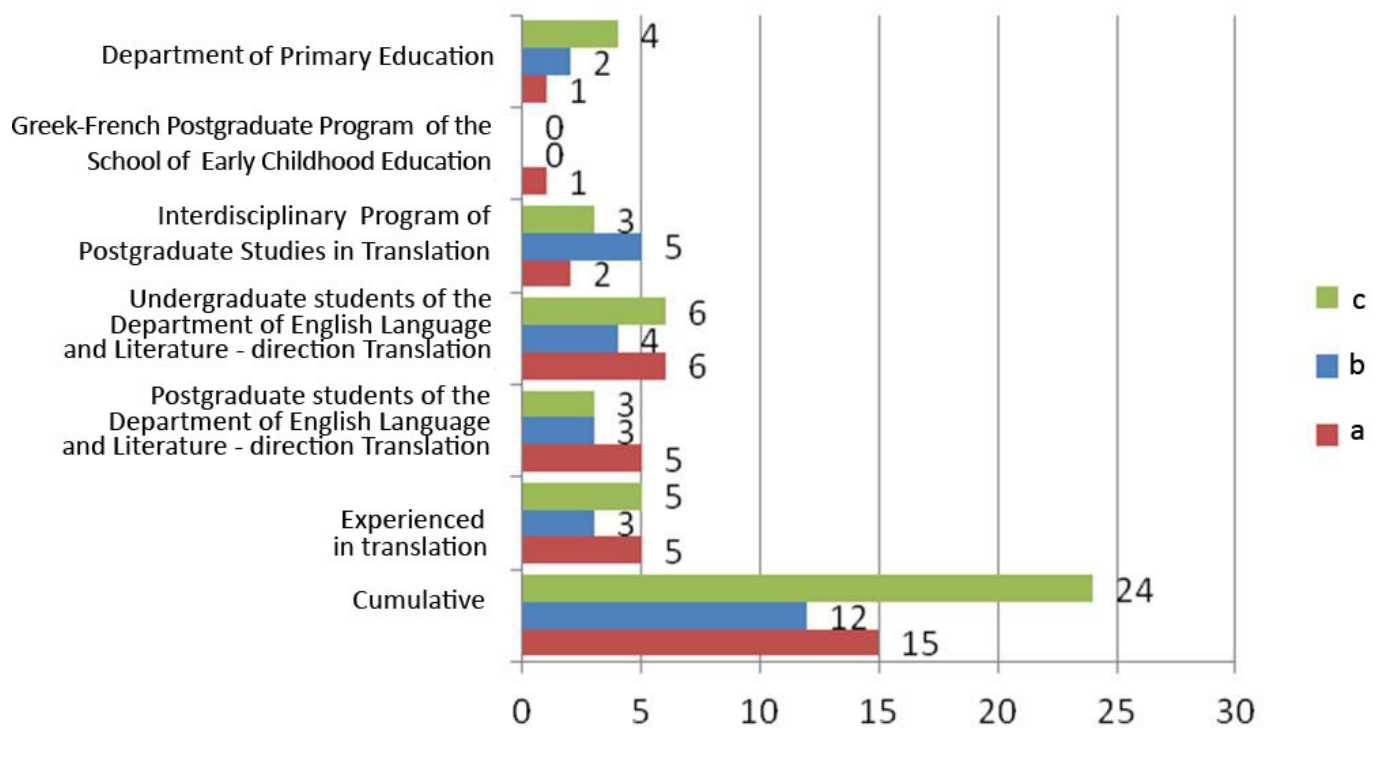

Figure 4. Statistics of question 6.

\section{Identification of Phrase Appropriateness}

In the first question all the participants, independently of their level of studies or professional experience in

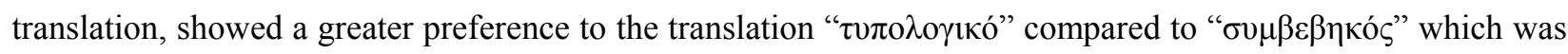
not considered so appropriate, as the answers to question $1 \mathrm{~b}$ also showed. According to the Dictionary of Linguistic and Phonetics by Crystal, the term "accidence" refers to the variations of the structure of a word which express grammatical concepts such as, case, number, tense, or gender. In Linguistics, these phenomena consist primarily an object of morphology that faces them as a process of word formation. On the other hand, as far as

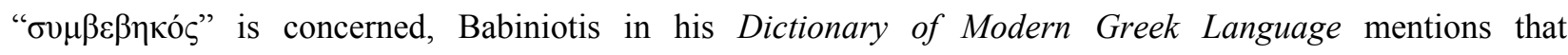

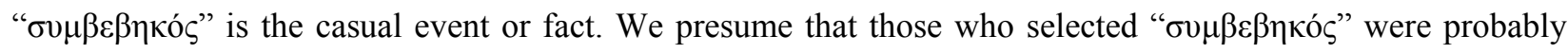
influenced by the English word "accident", i.e., " $\alpha \tau \cup \chi \chi \mu \alpha "$ ", which, nonetheless, in this particular case is not related to that being described in a linguistic context by the term accident, as it has been already mentioned. 


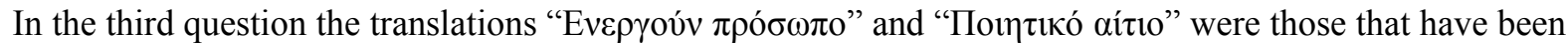
almost equally preferred as the cumulative comparison of results show, whereas the option " $\Delta \rho \alpha \dot{\sigma} \sigma \eta \varsigma^{\prime}$ " has been selected only by $3.9 \%$. The only category that presented a great diversion in the results was the one of

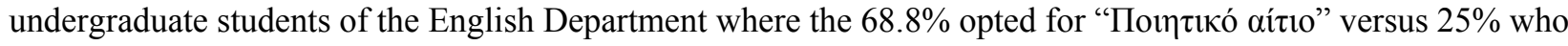

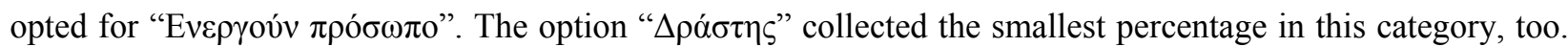

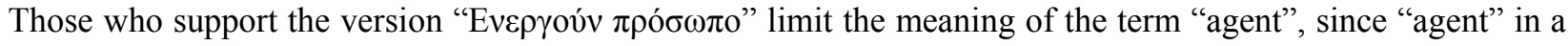
sentence can be a "person", as much as a concept, a natural phenomenon, or a thing. For example, in the sentence

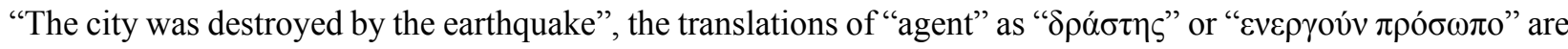
restrictive as they do not translate the term correctly.

In the sixth question a large diversification in the answers was observed. In cumulative results the option " $\mu \eta$ $\alpha \nu \varepsilon \xi \dot{\alpha} \rho \tau \eta \tau \eta \pi \rho \tau_{\tau} \alpha \sigma \eta$ " prevailed with a percentage of $47.1 \%$ versus $29.4 \%$ of the option " $\varphi \rho \alpha \dot{\sigma} \eta$ " and $23.5 \%$ of

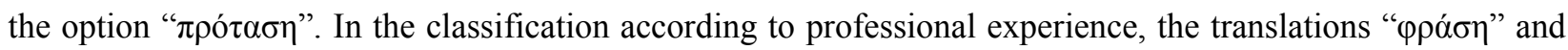

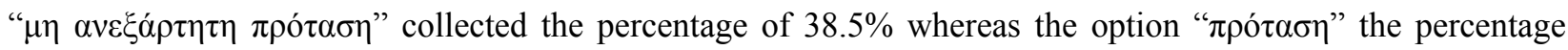
23.1\%. The undergraduate students of the Department of English Language and Literature also preferred equally

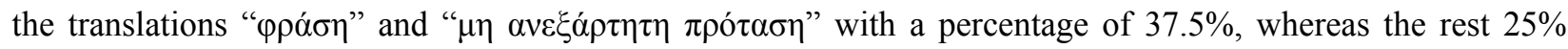
showed a preference towards the translation " $\pi \rho{ }^{\prime} \tau \alpha \sigma \eta$ ". In the category of the holders of post graduate degrees

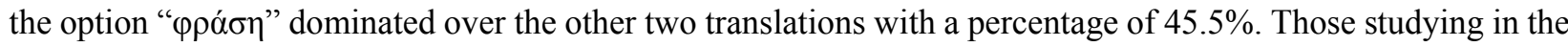
Interdisciplinary Program of Post-graduate Studies in Translation adopted the option " $\pi \rho$ ó $\tau \alpha \sigma \eta$ " at a 50\%

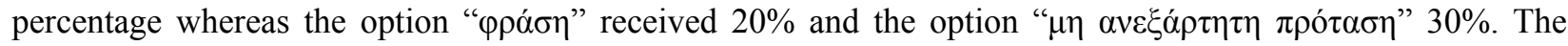
category of students of the Department of Primary Education the option " $\mu \eta \alpha v \varepsilon \xi \alpha \dot{\alpha} \rho \tau \eta \eta \eta \pi \rho$ ó $\tau \sigma \eta \eta$ ” was preferred

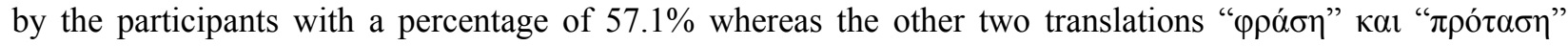
received $14.3 \%$ and $28.6 \%$ respectively. Here, it is evident that there is a difference in the way the English grammar perceives the term "clause" and in the way that this term is translated in the Greek grammar, despite the fact it comprehends the same meaning. According to the Dictionary of Linguistics and Phonetics by Crystal, the term refers to a unit of grammatical organization that is smaller than the sentence, but larger than phrases, words, or morphemes. Crystal (2008) goes on saying that these units are traditionally classified into main or subordinate clauses and adduces a representative example of both: "The girl arrived/after the rain started" (p. 78). In the same dictionary, on the section "phrase" it is reported that, as part of a structural hierarchy, the term "phrase" falls between clause and word, and additionally, on the section "sentence" is reported that the term "sentence" is the largest structural unit in terms of which the grammar of a language is organized. Therefore, in English, starting with the largest structural language unit and going to the smallest, the hierarchy is formed as follows: "sentence", "clause", and "phrase". However, in Greek, this distinction takes place with two structural units, the sentence and the next smallest, the phrase. Based on the Dictionary of Standard Modern Greek of Manolis Triandaphyllidis Foundation, a sentence is a group of words organized syntactically, having a verb as a prerequisite that expresses only one meaning usually formulated in short. As Dimitriou mentions in the Dictionary of Linguistic Terms that the simple form of a period (in the Greek sense) is called a sentence. According to traditional Linguistics, a sentence consists of a noun (subject) and a verb (predicate) and can constitute a full message, consequently it has a logical structure whereas a phrase has only got a syntactic structure (Dimitriou, 1994, p. 86, Vol. A). In the online dictionary The Free Dictionary, the definition of clause is mentioned that clause is a group of words consisting of 
a subject and a predicate, including a finite verb, and which does not necessarily constitute a sentence. Additionally, the Dictionary of Modern Greek Language by Babiniotis reports that, practically, instead of the term "period" the term "sentence" (" $\left.\pi \rho \tau_{\tau} \alpha \sigma \eta "\right)$ is used. In the Greek-English Dictionary of Linguistic Terms by Dimitriou the term "sentence" is rendered as "period-sentence", and the term "clause" is rendered as "sentence".

Thereafter, all the definitions indicate that the term "sentence" and the term "clause" are translated in Greek with the term "sentence" (" $\left.\pi \rho \tau^{\tau} \alpha \sigma \eta "\right)$. It is likely that some of the participants were mislead by their knowledge on "relative clauses" or the "wh-clauses" which are secondary clauses and consequently non-independent, and

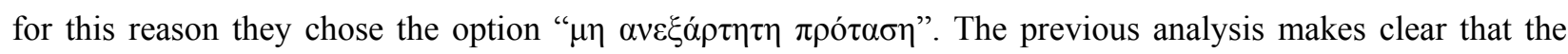
confusion about the translation of the term "clause" grew from the difference on this particular issue between the Greek and the English syntax, and the different opinions amongst the linguists.

\section{Presentation of Questionnaires With Suggested Correct Answers}

Table 7

$1^{\text {st }}$ Question - French

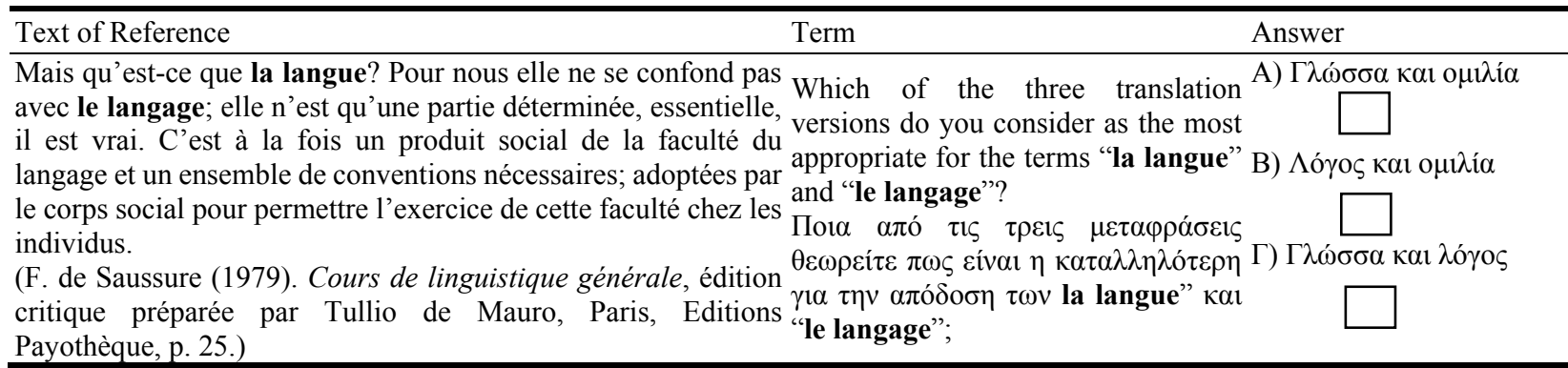

\section{$1^{\text {st }}$ question - French}

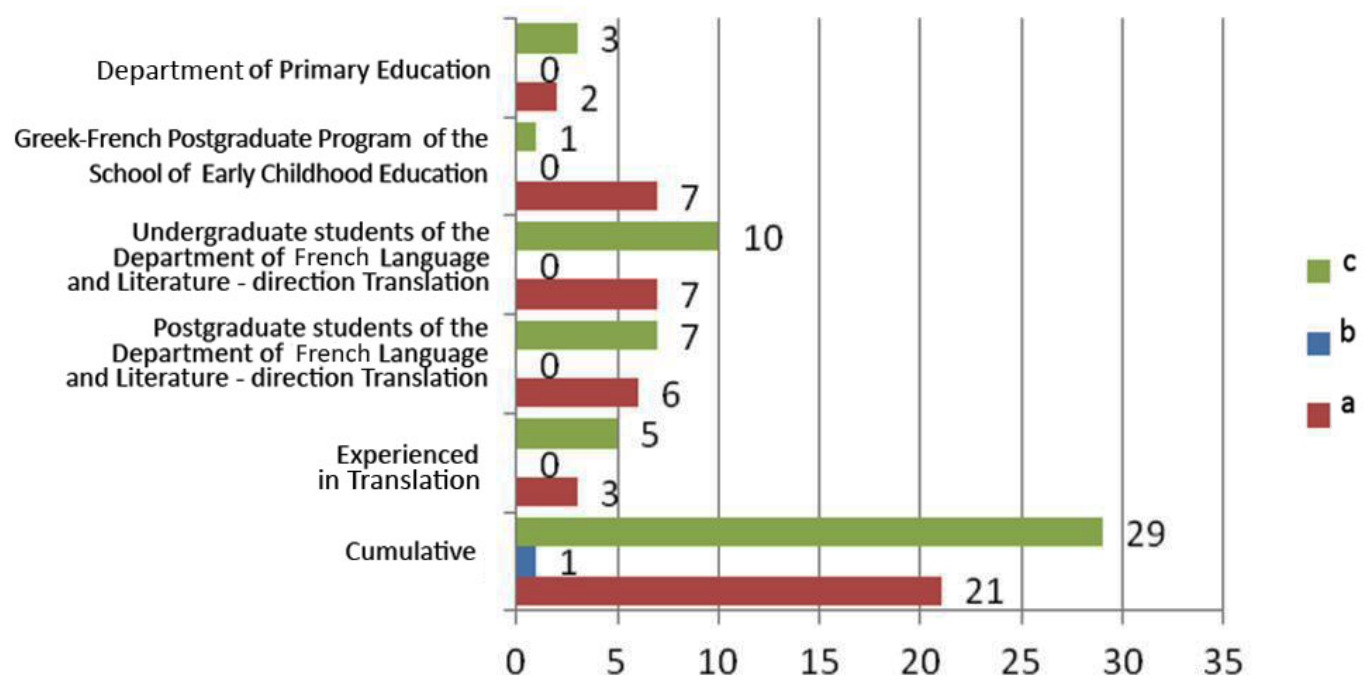

Figure 5. Statistics of question 1. 
Table 8

$2^{\text {nd }}$ Question - French

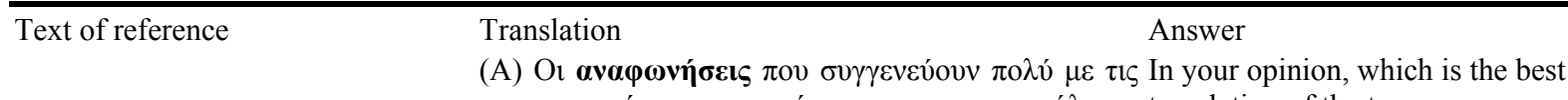

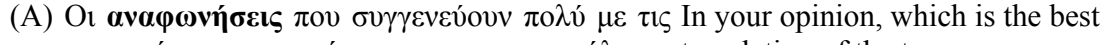

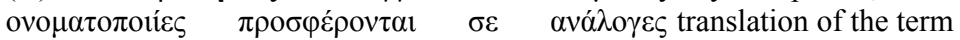

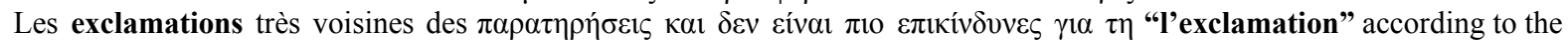
onomatopées, donnent lieu à des $\theta \dot{\varepsilon} \sigma \eta \mu$ s.

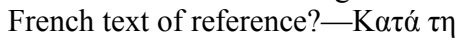

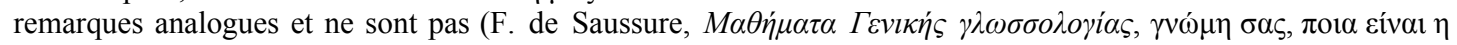

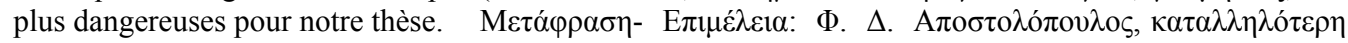

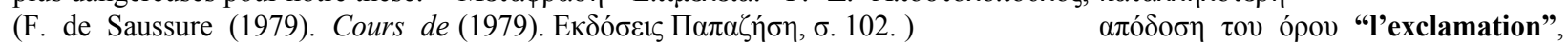

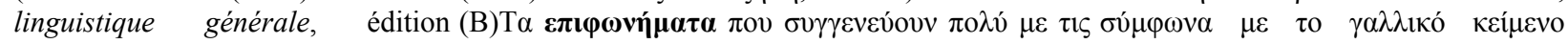

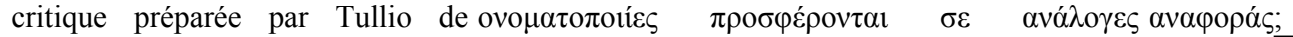

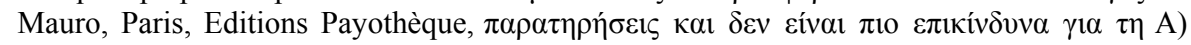
p. 102.) $\theta \dot{\varepsilon} \sigma \eta \mu \alpha$.

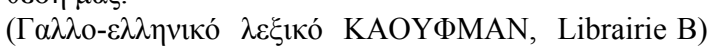
Kauffmann, A $\theta \dot{v} v \alpha, 2004$.)

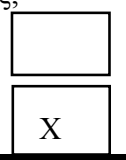

\section{$2^{\text {nd }}$ question - French}

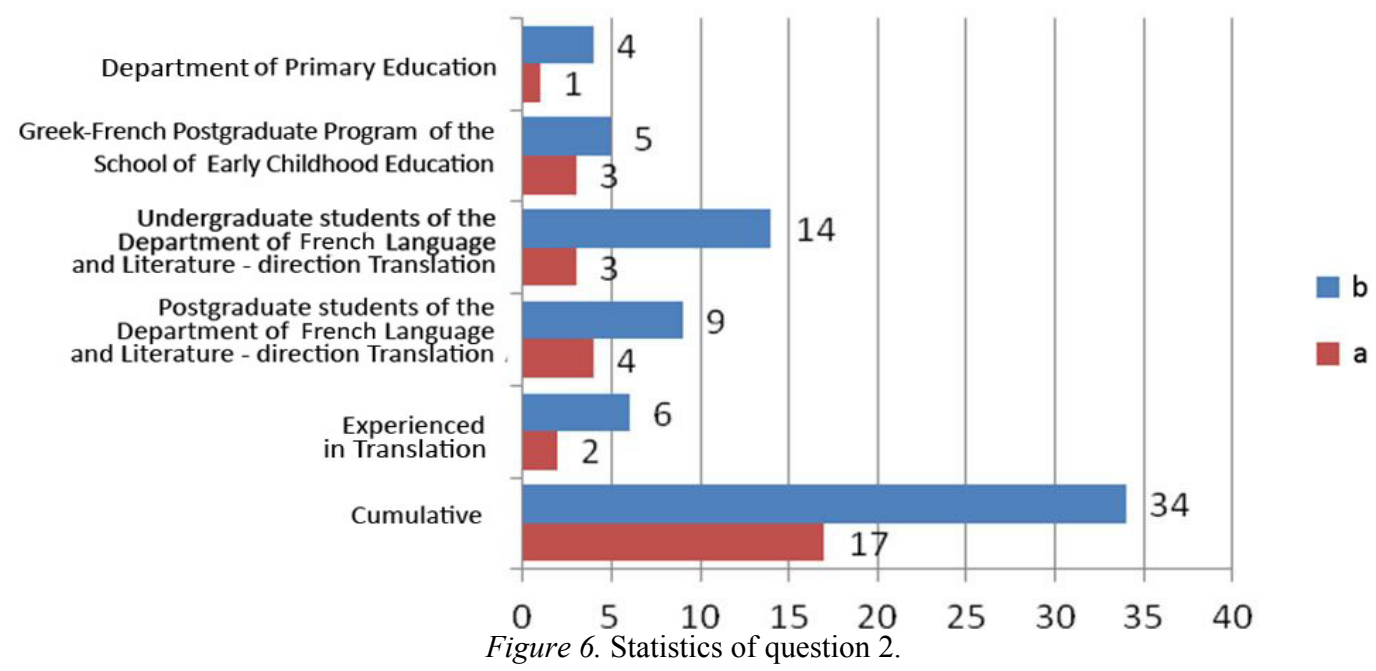

Table 9

$3^{\text {rd }}$ Question - French

\begin{tabular}{|c|c|}
\hline Text of reference & Translation \\
\hline $\begin{array}{l}\text { On a souvent considéré les processus de } \\
\text { renouvellement des moyens linguistiques comme } \\
\text { se plaçant en marge du fonctionnement normal de } \\
\text { la langue. On a même voulu y voir les } \\
\text { manifestations d'un langage affectif distinct du } \\
\text { langage grammatical. } \\
\text { (A. Martinet (1991). Eléments de linguistique } \\
\text { générale ,Troisième édition Editions Armand } \\
\text { Colin, 1991, p. 193.) } \\
\text { Définition du terme "le langage affectif": } \\
\text { "On appelle langage affectif ou expressif celui } \\
\text { qui traduit l'intérêt personnel que nous prenons à } \\
\text { nos paroles par une manifestation naturelle et } \\
\text { spontanée des formes subjectives de la pensée”. } \\
\text { J. Dubois, M. Giacomo, L. Guespin, C. Marcellesi, } \\
\text { J-B Marcellesi; J-P. Mével, Dictionnaire de } \\
\text { linguistique, Editions Larousse, 2002, p. 20. }\end{array}$ & 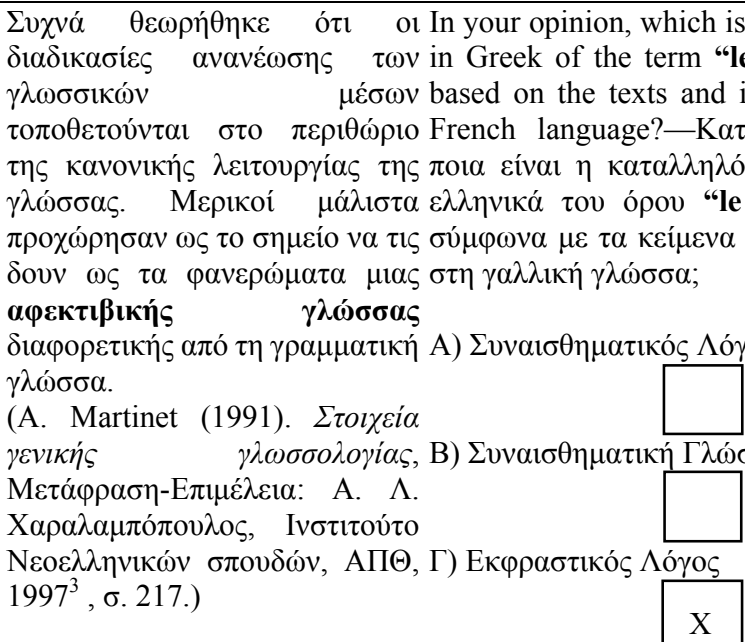 \\
\hline
\end{tabular}




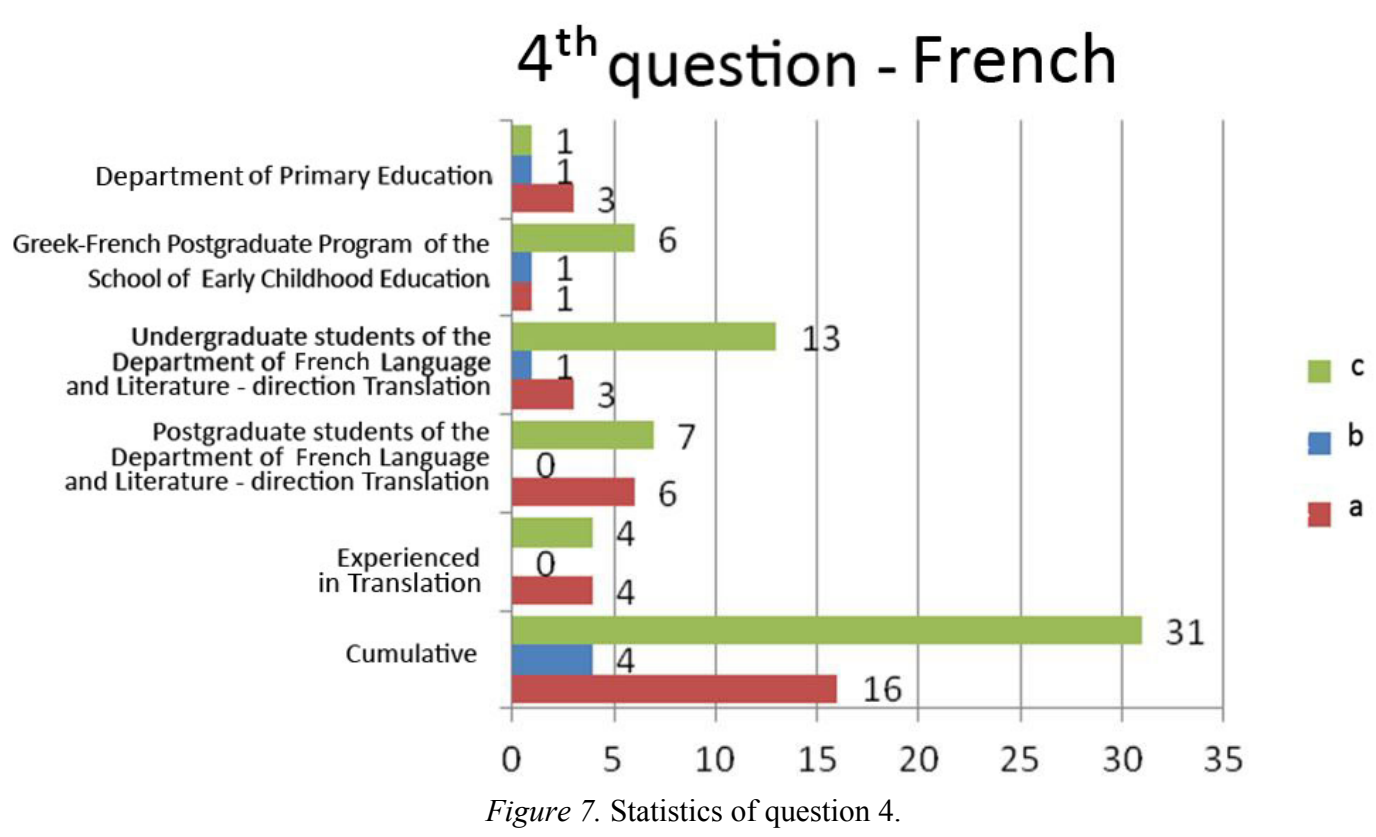

\section{Identification of Phrase Appropriateness}

In the first question of the French questionnaire regarding the rendering of "langue" $\kappa$ ar "langage" the results were somehow justified and expected, keeping in mind that there is not a complete identification in the translation of these terms as mentioned before. Statistically, the most popular choice was the option "Г

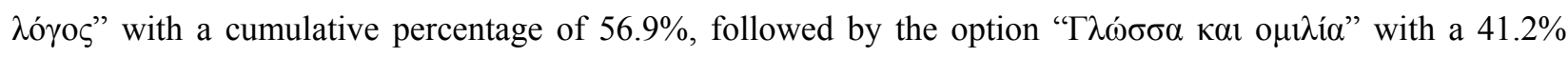

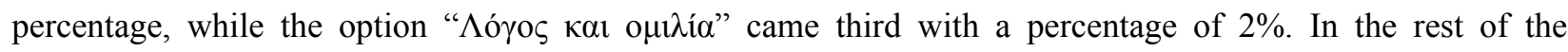

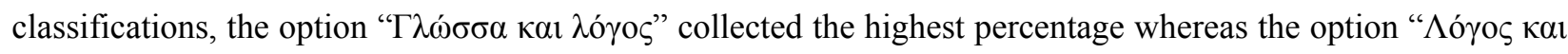
o $\mu \imath \lambda i \alpha$ " collected the lowest. The only exception to this was the category "Greek-French Postgraduate" in which

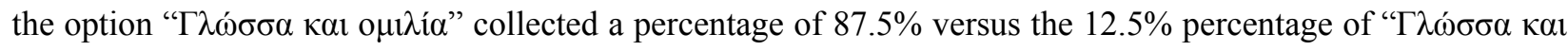
$\lambda$ ó $\gamma \circ \varsigma$ ". We can conclude that the students of the Greek-French Postgraduate Program were possibly influenced by the fact that in Greek the term "speech" often has the same meaning as the term "logos" (" $\lambda$ ó $\gamma \circ \varsigma$ "), as the dictionaries of Babiniotis and Triandaphyllidis Foundation also mention. In Larousse's French-to-French Terminology Dictionary, on the "langage" entry, this term is defined as the natural ability of man to communicate via a system of phonetic signals (i.e., the tongue as an instrument) activating a complex body technique and presupposes the existence of a symbolic operation and of the necessary by birth phonetic organs. In the same dictionary, on the "langue" entry, the term is defined as a tool of communication, a system of specific phonetic signals adopted by the members of a particular community.

In the second question of the French questionnaire and regarding the rendering of "exclamation", it is a fact that all of the participants, both in the cumulative results and in each separate category, opted for the option

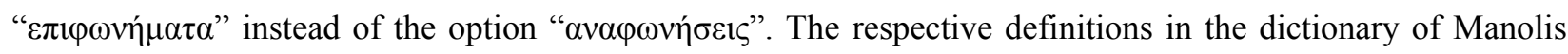

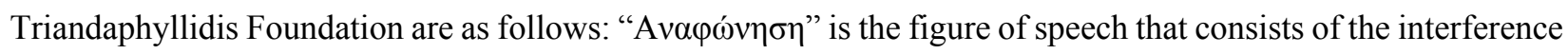
of exclamatory words or phrases in speech that bear the concept of invocation, wish, expression of admiration, etc. Exclamation is a voice or a non-inflected word that shows great emotion or feeling. The definitions presented in 
the Larousse dictionary are similar. The research in the aforementioned dictionary and also in the Greek-French Dictionary of the Tsigaridas Publications showed that the word "interjection" is used for the rendering of the

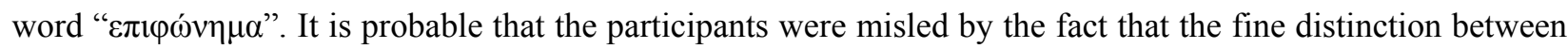

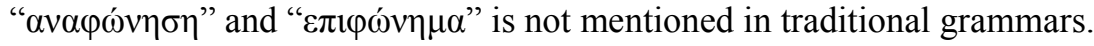

In the fourth question of the French questionnaires regarding the correct identification, knowledge or use of

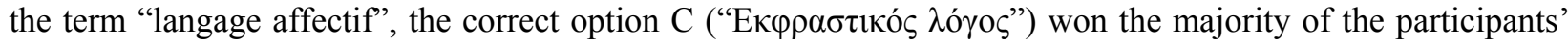
preferences. In the cumulative results the option A collected a percentage of $31.4 \%$ and the option B a percentage of $7.4 \%$, while $\mathrm{C}$ prevailed with a $60.8 \%$ percentage. The results in each separate category were the same with the exception of the students of the Early Childhood Education Department who gave a $60 \%$ percentage for the option A, and a $20 \%$ percentage for the other two options. According to the Larousse Linguistic Dictionary, the term "langage affectif" is defined as "that which is perceived as the personal interest that derives from our words through a natural and spontaneous manifestation of subjective forms of thinking" (Dubois, Giacomo, Guespin, Marcellesi, Marcellesi, \& Mével, 2002, p. 20).

\section{General Review-Questionnaires}

Through the processing of the questionnaires and the indexes but also through private conversations with experienced professional translators, we concluded that the translation of academic linguistic texts into the Greek language is a very difficult occupation due to the need for very high precision and clarity in translating the related terms.

We must admit, however, that the level of students, as revealed through the rest of their answers, was quite high. Regarding the English questionnaires, from a total of six questions, only two were answered incorrectly, highlighting in such way the failure to identify the correct translation of the relevant terms (Question 2 and Question 6).

Regarding the first question, we believe that this is due to the large dispute about the subject that still exists amongst the Greek linguists. In the second case, we assume that the respondents failed to locate the correct answer since they did not have the opportunity to attend contrastive linguistics courses during their studies. We believe that it would be particularly useful since, in this way, students will be able to understand better the pair of language systems in which they will be involved in the future, i.e., (1) their native language, of course and (2) the foreign language which they will be required to teach or to translate in the future.

We believe, therefore, that mastering the mother language, which is very often underestimated by the trainees in translation, by the professional translators themselves but also by their employers (Schäffner \& Adab 2000 , p. 7), is, for a future translator, a skill as important as the knowledge of the foreign language, since mastering the latter is not sufficient for the successful accomplishment of the translator's profession. In the present case, we believe that the training English teachers or the training translators would be able to solve successfully all the translation problems without any exception that had been set before them through the questionnaires if the aforementioned conditions existed.

Additionally, we believe that the future translators should specialize in one scientific field (Schäffner \& Adab, 2000, p. 4) and should focus practicing, of course, on a particular text type further more as it is not possible to become experts in everything. Perhaps the occupation with translation at undergraduate level should not focus 
only on literature but several fields should exist such as telecommunications, medicine, law, or finance, always of course conforming to the market needs.

As far as the French questionnaires are concerned, we have to say that the level of respondents was also very high. Out of a total of six questions, only two were answered incorrectly (Question 1 and Question 2). Concerning the first question (identification of correct translation), we believe that the respondents were not aware of the fine distinction between the proposed terms (i.e., exclamation) and therefore they chose the wrong answer. We consider that the suggestions and comments of English questionnaires regarding the education and practice of translators can also apply here.

What we can observe in both languages is that unresolved terminology issues (e.g., langue - langage - parole) do not have satisfactory and generally acceptable translation versions and even today different solutions are sought.

\section{Conclusion}

The results of the questionnaires showed a diversification of attitudes and choices of the translators of academic books and the research subjects and proved our hypothesis concerning the translation problem of linguistic terms in the Greek language as well as the controversy that exists in their translation. It would prove useful to extend the text sample to investigate the consolidation of the various terms in order that the understanding and deliberate use of translation strategies are achieved for creating terminology databases in each field by the translator himself.

One can observe that problematic terminology issues have not received adequate and generally acceptable translation options and even today different solutions are sought. Also, in the context of theoretical linguistics, terms which are ambiguous, are used with different meaning depending on the context (e.g., grammar - generative, traditional, descriptive, universal, and so on). We believe that the Greek theorists of linguistics should use, where possible, a uniquely identified terminology and should surely try, where necessary, to introduce into the Greek language neologisms with Greek and not "turned-into-Greek" words.

\section{Epilogue}

The survey with questionnaires indicates that on the part of the scientists there is a strong desire to build consensus and hence a standardized Greek terminology both in Linguistics and in the Telecommunications domain and that this constitutes a top priority. In particular, at university level, this should constitute a primary concern.

Those who will promote science in the future are being prepared by the academic community and it is necessary to teach them the use of national terminology, but above all the right use of the Greek language. Taking into account of course the current economic downturn of Greece but not ignoring the great importance of the use of the Greek language and the necessity that the Greek scientists have to be able to communicate in their native language, we believe that the state should ensure the existence of specialized translators in various university departments or even the creation of an official national body which will take on the task of verification, production, and dissemination of terminology issues in university departments. 
We believe that a result of this suggestion, would not only be the promotion of Greek language and terminology at national level but also the reassurance of a better and more effective communication between scientists, as well as the improvement of the provided teaching to students who will be able to study, through translation, the foreign-language bibliography without encountering ambiguities and problematic terms with double or even triple translation versions. Furthermore, we need to mention that the model of the present paper could be applied to other languages, such as German, provided that the inflow of terms and the need for text translation are great due to the economic and industrial development of this country and the impact it has on the Greek economy.

We hope that this paper will contribute towards this direction and that the resulting data will lead to better training of scientists and official translators as well as contribute to more efficient and qualitative science handbooks, bilingual glossaries, and terminology databases.

\section{References}

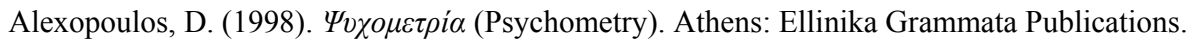

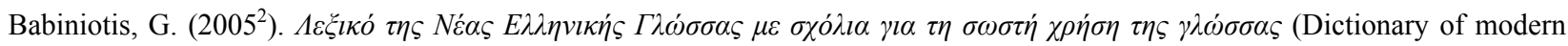
Greek language with annotations for the correct use of language). Athens: Lexicology Center.

Berman, A. (1999/1985). La traduction et la lettre ou L'auberge du lointain (Translation and the letter or the distant inn). Paris: Éditions du Seuil.

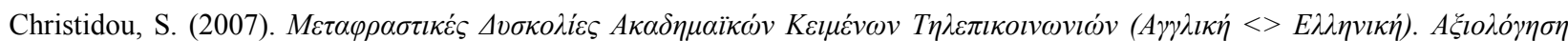

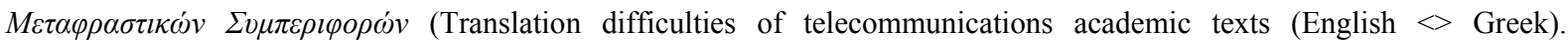
Evaluation of Translators' Behaviors). Retrieved from http://invenio.lib.auth.gr/record/100715/files/gri-2008-1031.pdf

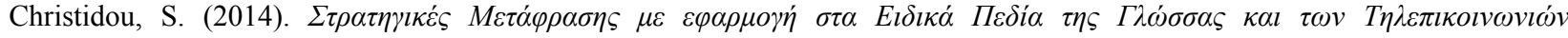
(Translation strategies with application in the special fields of linguistics and telecommunications). Florina, Thessaloniki: Iliadis Publications. (Three-member committee: Supervisor Kamaroudis E. Stavros: Associate Professor of The University of Western Macedonia, Chrysoulidis P. Dimitrios: Professor, School of Engineering, Department of Electrical and Computer Engineering, Fahantidis Nikolaos: Associate Professor, University Of Western Macedonia, Department of Informatics and Telecommunications Engineering.) Retrieved from http://www.didaktorika.gr/eadd/

Crystal, D. $\left(2008^{6}\right)$. A dictionary of linguistics and phonetics. Oxford: Blackwell Publishing.

Delabastita, D. (1989). Translation and mass communication: Film and T.V. translation as evidence of cultural dynamics. Babel, 35(4), 193-218.

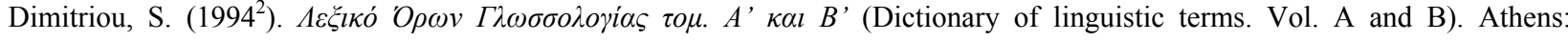
Kastaniotis.

Dubois, J., Giacomo, M., Guespin, L., Marcellesi, C., Marcellesi, J. B., \& Mével, J. P. (2002). Dictionnaire de linguistique (Dictionary of linguistics). Paris: Editions Larousse.

Hann, M. (1992). Technical translation Vl. 2 terminology/lexicography. Amsterdam/Philadelphia: John Benjamins.

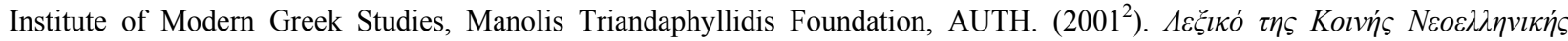
(Dictionary of standard modern Greek). Thessaloniki: Pelagia Ziti \& Co.

Koller, W. (1992/1978). Einführung in die Übersetzungswissenschaft (Introduction to the translation science). Heidelberg, Wiesbaden: Quelle \& Meyer.

Ladmiral, J. (1979). Traduire: théorèmes pour la traduction (Translating: Theorems for translation). Paris: Payot.

Lerat, P. (1995). Les langues spécialisées (Languages for special purposes). Paris: Presses universitaires de France.

Newmark, P. (1995). Approaches to translation. New York: Phoenix ELT.

Newmark, P. (2005). A textbook of translation. Essex, England: Longman.

Nord, C. (1997). Translating as a purposeful activity: Functionalist approaches explained. Manchester, United Kingdom: St. Jérôme.

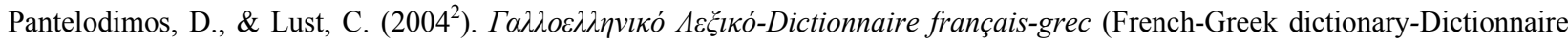
français-grec). Athens: Kaufmann. 


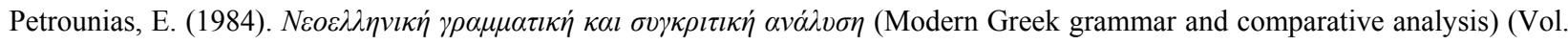
I). Thessaloniki: University Studio Press.

Random House Webster's unabridged dictionary. (1998). New York: Random House.

Reiss, K. (1983). Texttyp und Ubersetzungsmethode: D. operative Text. Kronberg/Heidelberg: Julius Groos Verlag.

Schäffner, C., \& Adab, B. (2000). Developing translation competence. Amsterdam/Philadelphia: John Benjamins.

Toury, G. (1995). Descriptive translation studies and beyond. Amsterdam/Philadelphia: John Benjamins.

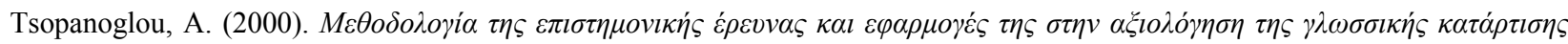
(Methodology of scientific research and applications to the evaluation of linguistic training). Thessaloniki: Ziti Publications.

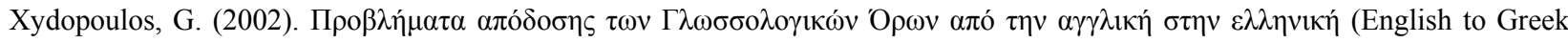
translation problems of linguistic terms). In Proceedings of the 22nd Annual Meeting of the Department of Linguistics (Studies of the Greek Language 22) (pp. 495-506). Thessaloniki: AUTH.

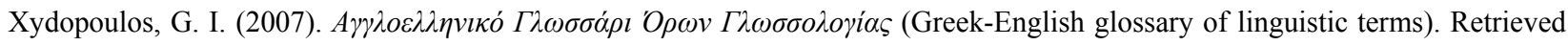
from http://users.uoi.gr/gjxydo/lexicon/glossary.html 